\title{
The Color Transmission in the Case of Cross Breed Sheep Belonging to the Black Karakul Variety
}

\author{
Ionică NECHIFOR ${ }^{1,2),}$ Constantin PASCAL ${ }^{1)^{*}}$, Marian FLOREA ${ }^{1,2)}$ \\ ${ }^{1)}$ Faculty of Animal Sciences, University of Agricultural Sciences and Veterinary Medicine, Iasi, 3 Mihail \\ Sadoveanu Alley, 700490 Iaşi, Romania \\ ${ }^{2}$ Agricultural Station of Research and Development for Sheep and Goat Growing Popauti-Botosani \\ *Corresponding author, e-mail: pascalc@uaiasi.ro
}

Bulletin UASVM Animal Science and Biotechnologies 72(2) / 2015

Print ISSN 1843-5262; Electronic ISSN 1843-536X

DOI:10.15835/buasvmcn-asb:11331

\begin{abstract}
The Karakul of Botoşani sheep breed raises genuine interest of breeders in North-Eastern Romania. Therefore, pelt quality assessment and studying of the mode of colour transmission are on-going activities for purposes of improvement. Lambs are obtained from the breeding of genitors belonging to the black colour variety. Breeding was based on matching pairs, involving 193 females, taking into account their line of origin and the pursued goal of the improvement. The appraisal method of transmission of colour and characteristics on which the quality of pelts depend was made in the first 24 hours after birth, based on the technical specifications and instructions in the certificate of origin, and productive values. Classification of lambs in relation to productive performances was done on the basis of the total final score. The study was conducted over a period of five generations of lambs obtained in calving seasons between 2010 and 2014. From the crossbreeding analysis of the genitors of black colour variety over several generations, it was established that $98 \%$ of the offspring had uniform black colour, but with different shades, and only $2 \%$ had other colours. This data allow us to conclude that the black colour specific of the Karakul of Botoşani sheep is a dominant type.
\end{abstract}

Keywords: Karakul of Botoşani, Romanian sheep, pelts

\section{INTRODUCTION}

In Romania, in the breeding area of Karakul of Botoşani sheep, there is a growing interest in production of pelts. This is due to demands that come from markets in the Republic of Moldova, the Ukraine and Russia, countries in which pelts of all varieties of colours are requested. In this context, the objective of the selection work for the Karakul of Botoșani breed is that each new generation of lambs should be superior to the previous one. To induce this aspect, the selection applied to the quality of curling of Karakul de Botoşani lamb pelts is intense and continuous. The basis of the genetic gain is represented by the testing of rams, starting from the assumption that the breeders are able to pass on their valuable qualities to their offsping (Pipernea, 1974). An important role in creating the kinds of colour or shades is that of small variations that occur within a population identified during the selection process. A primary role in the work of improvement has the prediction of quality traits in successive generations. To this end, we must establish the intensity of selection for other characteristics which however, are not subject to direct selection. For the work conducted in the field of improving the animals to be successful, attention must be paid to the following: understanding the theoretical base for the selection, connection between selection and genetics, knowing the hereditary particularities of traits which belong to the selection objective, 
organising the selection in the new conditions. (Pipernea, 1976).

\section{MATERIALS AND METHODS}

Research has been carried out on biological material that belongs to the Karakul of Botoșani breed, which is registered in the Genealogical Register of the breed. To increase data accuracy, data collection was extended over five successive generations of lambs obtained in breeding and calving seasons throughout 2010-2015.

Reproduction applied was based on crossing the genitors belonging to the black colour variety, and for each breeding season reproduction was based on the development and enforcement of a homogeneous routing mating list. This document was previously developed after careful analysis of specific particularities and features specific to the parenting form. This was done so that the effect on the properties and quality of pelts from the new generations of lambs to be quantifiable and more easily highlighted.

Each year the breeding season was between the months of September and October, and the fecundation process was based on mounting. For the livestock to display the best breeding function, with 30 days before the fixed date for the onset of reproduction, they were subjected to a period of intensive feeding, a fact that allowed the breeding activity to extend only for the duration of two sexual cycles.

Evaluation of quality features and traits which impact the quality of pelts was performed in the first 24 hours after birth, and to have the same assessment of the requirements, the work was done by the same authorized person.

\section{RESULTS AND DISCUSSIONS}

The main productive feature specific to the Karakul of Botoşani breed is the manner in which the hair coverage of the pelts is arranged. Generally, the pelt is characterized by beauty and outstanding reflexes, conferred by the basic colour, by the pattern and uniformity of curls, gloss, silkiness and other particularities. The quality of pelts conferred to the fur is attributed to slaughtering the lambs in the first days after birth, when the follicle shell presents a specific aspect, in the form of curls, giving a special aesthetic aspect.

Thanks to the occurrence of new types of pelts and to farmers' interest in valuable biological qualities, the Karakul of Botoşani breed has known a steady expansion in areas located in the North-East of Romania (Pascal, 2011). At present, in Romania, in the selection of Karakul of Botosani sheep, breeders pursue the specific characters of the pelts with flattened curls, a tendency imposed by Namibian and South African researchers (Tafta et al., 1997, Clote et al., 2014, Bravenboer, 2007).

After the year 2007 the genealogical registers was set up for each sheep breed, and for Karakul of Botosani the activity and the work of testing and evaluation of breeders is managed by ACOOC Moldoovis from Botoşani. The Genealogical Register of Karakul of Botosani sheep is structured as follows:

1. Principal Genealogical Register.

2. Additional Register (Secondary).

To be included in one of the sections in question, any proposed individual must fulfil certain requirements that can be tracked, evaluated and determined. The present situation of the individuals belonging to the Karakul of Botoşani breed included in the two sections is presented in table 1 . Analysing the data presented in Table 1, it can be seen that the most numerous nucleus is located in Botoşani, and in Vaslui and Iași the percentage of the herds which can be found in the Genealogical Register of the breed is only $15 \%$. The high interest for and tradition in growing this breed and the farmers' attachment to the behaviour, biology and specificity of the product obtained from this breed is reflected in the present situation of the livestock. If in Neamt and Suceava the Karakul of Botoşani sheep herds entered in the register of the breed are $4.1 \%$ and $1.98 \%$, respectively, in Bacău County there are no

Tab. 1. Present situation of the size of Karakul of Botoşani sheep herds included in the Genealogical Register

\begin{tabular}{c|c|c}
\hline County & $\begin{array}{c}\text { No. of } \\
\text { individuals }\end{array}$ & $\begin{array}{c}\text { Frequency } \\
(\%)\end{array}$ \\
\hline Botoşani & 3416 & 63.72 \\
\hline Vaslui & 860 & 16.04 \\
\hline Iaşi & 759 & 14.16 \\
\hline Neamț & 220 & 4.10 \\
\hline Suceava & 106 & 1.98 \\
\hline Bacău & - & - \\
\hline TOTAL & 5361 & 100.00 \\
\hline
\end{tabular}


individuals included in this register which certifies the origin of the quality of the biological material (Nechifor, et al, 2014).

Concluding, it can be said that in the growing area of the Karakul of Botoşani sheep, interest is directed towards obtaining pelts with new characteristics, particularly glossy and with original curl patterns.

Regarding the colour of pelts, it can be said that black is the wanted one, followed by smoky, grey, brown and white. Within each variety, depending on various factors and matings, various shades of colour appear that can increase the commercial value and beauty of pelts.

Coming in response to these trends, research focused on evaluating the method of colour transfer in the case of genitor mating belonging to black colour variety, but also on analysing the incidence of valuable shades of black. In this regard, the transmission of colours within this type of cross was analysed for five years. Five rams were used for mating, which are part of the male nursery group certified for this purpose. The base of the reproduction activity was matching pairs using 193 females, taking into account their origin, lineage and the intended purpose for improvement.

Table 2 summarizes colour transmission resulting from the crossing of the five black rams with ewes of the same black variety, during four breeding seasons. Analysing the resulting values, it becomes apparent that $96.8 \%$ of the total number of lambs obtained had black colour, while the percentage of lambs with other colours was about $2 \%$.
It was observed that depending on the density and more or less uniform distribution of melanocytes, in mating between black colour genitors, the following shades also occur: bluish black (with lustre); plain black (with diminished lustre); foxy black (diminished lustre, less appreciated).

Analysing data relating to the shades resulted within the dominant base colour, it becomes apparent that the type of black pelt with bluish shimmer was identified in only $25 \%$ of the total number of lambs resulting from crosses of black colour genitors. Of the total rams used for mating, code R05 stands out because it transmitted the wanted colour - black with bluish reflections - to its progeny very well (92.3\%). Based on these results, we can conclude that this breeder should be used more intensively for breeding because of the quality proven as breeder for the base colour. All these values are close to those published in other scientific papers (Pascal et al, 2010, Pascal, 2011).

Homogeneous breeding practiced among breeders of black colour sheep result in a relatively large share, over $20 \%$, of black lambs but with a poorly expressed gloss, showing that for the breed Karakul of Botoşani selection work must be intensified, and promoting rams in the group that can be used in breeding should be done after testing the ram's performance and the way it conveys the desired character wanted for descendants.

Analysis of the mode of transmission of colour in Karakul of Botoșani indicates that the black colour is given by two different genotypes, namely

Tab. 2. Transmission of colour and shades at Karakul of Botoşani breed, black variety

\begin{tabular}{|c|c|c|c|c|c|c|c|c|c|c|c|}
\hline \multirow{3}{*}{ Ram code } & \multirow{3}{*}{$\begin{array}{c}\text { Total } \\
\text { obtained } \\
\text { lambs }\end{array}$} & \multicolumn{4}{|c|}{ Colour } & \multicolumn{6}{|c|}{ Shades of colour } \\
\hline & & \multicolumn{2}{|c|}{ black } & \multicolumn{2}{|c|}{$\begin{array}{l}\text { other colours } \\
\text { (brown, gray, } \\
\text { etc.) }\end{array}$} & \multicolumn{2}{|c|}{$\begin{array}{l}\text { bluish } \\
\text { black }\end{array}$} & \multicolumn{2}{|c|}{ plain black } & \multicolumn{2}{|c|}{ mat black } \\
\hline & & no. & $\%$ & no. & $\%$ & no. & $\%$ & no. & $\%$ & no. & $\%$ \\
\hline R01 & 55 & 52 & 94.6 & 3 & 5.4 & 11 & 21.2 & 29 & 55.8 & 12 & 23.0 \\
\hline R02 & 67 & 66 & 98.5 & 1 & 1.5 & 12 & 18.2 & 37 & 56.1 & 17 & 25.7 \\
\hline R03 & 27 & 25 & 92.6 & 2 & 7.4 & 1 & 4.0 & 14 & 56.0 & 10 & 40.0 \\
\hline R04 & 28 & 28 & - & - & - & 10 & 35.7 & 17 & 60.7 & 1 & 3.6 \\
\hline R05 & 13 & 13 & - & - & - & 12 & 92.3 & 1 & 7.7 & - & - \\
\hline Total & 190 & 184 & 96.8 & 6 & 3.2 & 46 & 25.0 & 98 & 53.3 & 40 & 21.7 \\
\hline
\end{tabular}


dominant black and recessive black dominant. These genotypes are distinguished from each other by the fact that the recessive one favours the occurrence of other colours, often brown and grey.

\section{CONCLUSIONS}

1. Analysis of Karakul of Botoșani livestock entered in the Genealogical Register shows that over $60 \%$ is represented by herds in the farms situated in the area of breed development.

2 . In the case of homogeneous breeding belonging to black colour variety, it has been found that $96.8 \%$ of the total number of lambs obtained had black colour, while the share of lambs of other colours was about $2 \%$.

3. The fact that the Karakul of Botoșani has a share of $2 \%$ of a different colour confirms that the black colour is given by two different genotypes, namely dominant black and recessive black, and that these genotypes differ from each other by the fact that the recessive one favours the occurrence of other colours, often brown and grey.

4. From the group of the five rams use in mating, the one coded R05 stands out because it transmitted the wanted colour - black with bluish reflections - to close to $93 \%$ of its descendants.

5. Based on these results we can say that some of the followed breeders should be used more intensively in breeding because of quality improvement.

\section{REFERENCES}

1. Bravenboer B, (2007). Karakul. Gift from the arid land Namibia 1907-2007, Karakul Board of Namibia, ISBN 9991668896, 9789991668895, 382 pag

2. Clote SWP, Olivier JJ, Sandenbergh L, Snyman MA (2014) The adaption of the South Africa sheep industry to new trends in animal breeding and genetics. S. Afr. J. Anim. Sci., 44:307-321

3. Nechifor I, Pascal C, Nechifor C. (2014) Studies regarding the application effect of productive control techniques on improvement of Karakul lamb skins quality, Lucrări Ştiințifice, Seria Zootehnie, ISSNL 1454-7368, 60: 76-81

4. Pascal C. (2011) Researches regarding quality of sheep skin obtained from Karakul Botosani sheep, Biotechnology in Animal Husbandry Belgrad, ISSN 1450-9156, 27:11231131

5. Pascal C, Ivancia M, Hrincă Ghe, Chiorescu I. (2010) Researches regarding quality of sheep skins obtained from Karakul from Botosani sheep, al XX-lea Congres Internațional al Asociației Maghiară de Buiatrie, ISBN 978-963-87942-3-9, p. 204-209

6. Pipernea N. (1974) Heredity of main character and qualities of the domestic animals. Ed. Ceres BucharestRomania.

7. Pipernea N. (1976) Improvement of the genetic structure of animal populations. Ed. Ceres Bucharest-Romania.

8. Taftă V, Vintilă I, Zamfirescu S. (1997). Production, improvement and reproduction of sheep. Ed. Ceres Bucharest-Romania. 